INOBIS: Jurnal Inovasi Bisnis dan Manajemen Indonesia

Volume 1, Nomor 4, September 2018

Dyah Sawitri; Wisma Miftahur Rozi; Gendut Budi Wahyono; Eko Budi Siswandoyo

\title{
Pengaruh Kualitas Pelayanan Jasa Dan Kualitas Harga Terhadap Kepuasan Konsumen Pada Hotel Purnama Dimediasi Oleh Kepercayaan
}

\author{
Dyah Sawitri \\ Universitas Gajayana Malang \\ dyahsawitri19@yahoo.com \\ Wisma Miftahur Rozi \\ Alumni Program Pascasarjana Universitas Gajayana Malang \\ wisma.mifta@gmail.com \\ Gendut Budi Wahyono \\ Universitas Gajayana Malang \\ gendut.budi@unigamalang.ac.id \\ Eko Budi Siswandoyo \\ Universitas Gajayana Malang \\ brynasiswandoyo@gmail.com
}

\begin{abstract}
Abstrak
Latar belakang penelitian adalah Salah satu kegiatan yang menunjang pariwisata Kota Batu adalah penyediaan akomodasi berupa tempat-tempat penginapan yang memadai bagi wisatawan yang masuk Kota Batu. Puluhan Hotel berbintang dan ratusan hotel non bintang seperti homestay dan vila, siap menyediakan fasilitas akomodasi bagi pengunjung Kota Wisata Batu. Peningkatan jumlah hotel tersebut merupakan indikator yang menunjukkan semakin tingginya persaingan jasa perhotelan. Salah satu indikator keberhasilan hotel dalam memperoleh pelanggan adalah dengan memberikan jaminan kepuasan. kepuasan konsumen adalah perasaan senang atau kecewa seseorang yang muncul setelah membandingkan kinerja (hasil) produk/jasa yang dipikirkan terhadap kinerja (hasil) yang diharapkan.

Kepusan merupakan salah satu indicator keberhasilan dalam kinerjanya sehingga dapat menjamin terjadinya loyalitas pelanggan. Tujuan dari penelitian ini adalah : (1) Untuk mengetahui dan menganalisa pengaruh yang signifikan kualitas pelayanan jasa terhadap kepuasan konsumen pada Hotel Purnama, (2) Untuk mengetahui dan menganalisa pengaruh yang signifikan kualitas harga terhadap kepuasan konsumen pada Hotel Purnama, (3) Untuk mengetahui dan menganalisa pengaruh yang signifikan kualitas pelayanan jasa terhadap kepercayaan konsumen pada Hotel Purnama, (4) Untuk mengetahui dan menganalisa pengaruh yang signifikan kualitas harga terhadap kepercayaan konsumen pada Hotel Purnama.

Jenis penelitian yang digunakan merupakan penelitian kuantitatif, dengan jumlah sampel penelitian sebanyak 87 pelanggan, analisis data menggunakan model struktur (Inner Model).Hasil penelitian menunjukkan variabel kualitas pelayanan, kualiats harga berpengaruh positif terhadap kepuasan pelanggan.
\end{abstract}

Kata kunci: Kualitas pelayanan, kualitas harga, kepuasan pelangan 
INOBIS: Jurnal Inovasi Bisnis dan Manajemen Indonesia

Volume 1, Nomor 4, September 2018

Dyah Sawitri; Wisma Miftahur Rozi; Gendut Budi Wahyono; Eko Budi Siswandoyo

\section{Pendahuluan}

Puluhan Hotel berbintang dan ratusan hotel non bintang seperti homestay dan vila, siap menyediakan fasilitas akomodasi bagi pengunjung Kota Wisata Batu. Menjadi salah satu kota tujuan wisata yang utama di Jawa Timur, telah disadari oleh masyarakat Kota Batu sehingga dari waktu ke waktu bermunculan usaha jasa akomodasi berupa Hotel Berbintang dan hotel Non Bintang, restoran / rumah makan, Pusat perbelanjaan / Mall dsb. Pertumbuhan jumlah hotel di Kota batu saat ini terus mengalami kenaikan. Peningkatan jumlah hotel di Kota batu tersebut diikuti oleh peningkatan Tingkat Penghunian Kamar (TPK) yang merupakan salah satu indikator yang menggambarkan produktivitas suatu hotel. Tingkat Penghunian Kamar (TPK) di Kota Batu secara total mencapai 27,49\% pada tahun 2014 dan meningkat menjadi 37,99\% pada tahun 2015. Angka TPK sebesar 37.99\% itu mempunyai arti bahwa pada tahun 2015, bila ada 1000 kamar tersedia maka rata-rata yang di huni tamu sebanyak 379 kamar (BPS, 2016).

Salah satu indikator keberhasilan hotel dalam memperoleh pelanggan adalah dengan memberikan jaminan kepuasan. Menurut Engel (1995) dalam (Hasan, 2008:56) kepuasan merupakan evaluasi purnapakai/purnabeli dimana alternatif yang dipilih sekurang-kurangnya sama atau melampaui harapan pelanggan, sedangkan ketidakpuasan timbul apabila hasil tidak memenuhi harapan. Sedangkan Menurut Kotler (2010:177), kepuasan konsumen adalah perasaan senang atau kecewa seseorang yang muncul setelah membandingkan kinerja (hasil) produk/jasa yang dipikirkan terhadap kinerja (hasil) yang diharapkan. Dalam bisnis jasa kepuasan merupakan salah satu indikator keberhasilan dalam kinerjanya sehingga dapat menjamin terjadinya loyalitas pelanggan.

Banyak faktor yang dapat mempengaruhi kepuasan pengguna hotel, salah satunya adalah kualitas pelayanan. Kualitas pelayanan merupakan suatu fenomena yang unik, sebab dimensi dan indikatornya dapat berbeda diantara orang-orang yang terlibat dalam pelayanan.

Salah satu usaha perhotelan di Kota Batu merupakan salah sotu hotel bintang 4 adalah Hotel Purnama. Dengan kondisi perekonomian belakangan ini yang kurang cerah dan persaingan antar hotel sendiri yang semakin ketat harusnya mendorong sebuah usaha hotel salah satunya adalah Hotel Purnama untuk berlomba-lomba meningkatkan kualitas jasa pelayanannya sebagai usaha untuk memenangkan persaingan. Adapun dasar dari pemilihan Hotel Purnama Batu sebagai objek penelitian ini karena pertimbangan bahwa hotel Purnama memiliki angka TPK sebesar 49,98\% itu mempunyai arti bahwa pada tahun 2015, bila ada 1.000 kamar tersedia maka rata-rata yang di huni tamu sebanyak 498 kamar (BPS, 2016).

Tabel 1.

Data Perbandingan Hotel Bintang 4 Di Kota Batu

\begin{tabular}{|l|c|c|l|}
\hline Nama Hotel & TPK & $\begin{array}{c}\text { Rating } \\
\text { Traveloka }\end{array}$ & Kategori \\
\hline $\begin{array}{l}\text { Purnama } \\
\text { Hotel }\end{array}$ & $49,98 \%$ & 8.5 & $\begin{array}{l}\text { Sangat } \\
\text { Baik }\end{array}$ \\
\hline $\begin{array}{l}\text { Amartahills } \\
\text { Hotel and } \\
\text { Resort Batu }\end{array}$ & $48,37 \%$ & 8.7 & $\begin{array}{l}\text { Sangat } \\
\text { Baik }\end{array}$ \\
\hline $\begin{array}{l}\text { Kusuma } \\
\text { Agrowisata } \\
\text { Resort and } \\
\text { Convention }\end{array}$ & $48.31 \%$ & 8.4 & $\begin{array}{l}\text { Sangat } \\
\text { Baik }\end{array}$ \\
\hline
\end{tabular}


INOBIS: Jurnal Inovasi Bisnis dan Manajemen Indonesia Volume 1, Nomor 4, September 2018

Dyah Sawitri; Wisma Miftahur Rozi; Gendut Budi Wahyono; Eko Budi Siswandoyo

\begin{tabular}{|l|c|c|l|}
\hline Hotel & & & \\
\hline $\begin{array}{l}\text { Klub Bunga } \\
\text { Butik Resort }\end{array}$ & $47.12 \%$ & 8.3 & $\begin{array}{l}\text { Sangat } \\
\text { Baik }\end{array}$ \\
\hline $\begin{array}{l}\text { Kartika } \\
\text { Wijaya }\end{array}$ & $46.17 \%$ & 8.5 & $\begin{array}{l}\text { Sangat } \\
\text { Baik }\end{array}$ \\
\hline $\begin{array}{l}\text { Royal } \\
\text { Orchids } \\
\text { Garden Hotel } \\
\text { \& } \\
\text { Condominium }\end{array}$ & $45.33 \%$ & 8.3 & $\begin{array}{l}\text { Sangat } \\
\text { Baik }\end{array}$ \\
\hline $\begin{array}{l}\text { Batu Suki } \\
\text { Resort \& } \\
\text { Hotel }\end{array}$ & $39.77 \%$ & 7.8 & Baik \\
\hline $\begin{array}{l}\text { Villa Della } \\
\text { Scala }\end{array}$ & $38.19 \%$ & 7.7 & Baik \\
\hline
\end{tabular}

Sumber : BPS (2016) Traveloka.com (2017)

Berdasarkan data TPK dan penilaian rating dapat diketahui bahwa tingkat hunian kamar untuk Hotel Purnama paling tinggi walaupun penilaian traveloka menunjukkan peringkat dua. Sebagai perusahaan yang bergerak di bidang jasa, Hotel Purnama harus bisa memberikan kepuasan akan pelayanannya. Data pengunjung Hotel Purnama per 3 tahun terakhir disajikan pada Tabel 2.

Tabel 2.

Data Pengunjung Hotel Purnama

\begin{tabular}{|c|c|c|c|}
\hline $\begin{array}{c}\text { Jumlah } \\
\text { Pengunjun } \\
\mathrm{g}\end{array}$ & $\begin{array}{c}\text { Tahu } \\
\text { n } \\
2014\end{array}$ & $\begin{array}{c}\text { Tahu } \\
\text { n } \\
2015\end{array}$ & $\begin{array}{c}\text { Tahu } \\
\text { n } \\
2016\end{array}$ \\
\hline Domestik & $\begin{array}{c}48.32 \\
6\end{array}$ & $\begin{array}{c}49.40 \\
7\end{array}$ & $\begin{array}{c}51.30 \\
4\end{array}$ \\
\hline $\begin{array}{l}\text { Mancanegar } \\
\text { a }\end{array}$ & $\begin{array}{c}11.57 \\
0\end{array}$ & $\begin{array}{c}10.98 \\
7\end{array}$ & $\begin{array}{c}11.45 \\
0\end{array}$ \\
\hline & $\begin{array}{c}59.89 \\
6\end{array}$ & $\begin{array}{c}60.39 \\
4\end{array}$ & $\begin{array}{c}62.75 \\
4\end{array}$ \\
\hline
\end{tabular}

Sumber : Data diolah peneliti, Tahun 2017

Berdasarkan data tersebut menunjukkan bahwa Terdapat peningkatan yang cukup signifikan pengunjung hotel purnama selama tiga tahun terakhir. Hal tersebut merupkana hasil dari kualitas pelayanan yang baik. Selain kualitas pelayanan yang didukung dengan karyawan yang terampil dan terlatih, Hotel Purnama juga memiliki biaya atau harga yang standart. Harga merupakan salah satu faktor penting dalam penjualan. Banyak perusahaan yang bangkrut dikarenakan mematok harga yang tidak cocok di pasar. Untuk mengetahui harga yang cocok untuk konsumen, perusahaan harus melakukan riset yang mendalam agar dapat menentukan harga yang cocok untuk konsumen Sehingga perusahaan dapat melakukan transaksi jual beli secara lancar. Bagi perusahaan harga tersebut akan memberikan hasil dengan menciptakan sejumlah pendapatan dan keuntungan bersih (Swasta, 2008). 
INOBIS: Jurnal Inovasi Bisnis dan Manajemen Indonesia

Volume 1, Nomor 4, September 2018

Dyah Sawitri; Wisma Miftahur Rozi; Gendut Budi Wahyono; Eko Budi Siswandoyo

\section{Metode Penelitian}

Menurut (Sugiyono, 2012), metode survey adalah metode yang digunakan untuk mendapatkan data dari tempat tertentu yang alamiah (bukan buatan), dimana peneliti melakukan perlakuan dalam pengumpulan data, misalnya dengan mengedarkan kuisioner, tes, wawancara terstruktur, dan sebagainya. Jenis penelitian yang dilakukan adalah explanatory research (penelitian penjelasan). Menurut (Singarimbun dan Sofian Effendi, 2009), explanatory research adalah suatu penelitian dimana peneliti menjelaskan hubungan kausal sebab akibat antara variabel-variabel melalui pengujian hipotesa.

Pendekatan dalam penelitian ini adalah pendekatan kuantitatif, karena penelitian ini disajikan dengan angka-angka. Hal ini sesuai dengan pendapat (Arikunto, 2010) yang mengemukakan penelitian kuantitatif adalah pendekatan penelitian yang banyak dituntut menggunakan angka, mulai dari pengumpulan data, penafsiran terhadap data tersebut, serta penampilan hasilnya. Data dalam penelitian ini dikumpulkan dengan menggunakan kuesioner, dari hasil kuesioner tersebut dianalisis untuk mengetahui pengaruh masing-masing variabel yang dihitung menggunakan PLS.

Anggota sampel yang digunakan dalam metode penelitian ini adalah 87 sampel.Kemudian peneliti membagi sampel yang digunakan yakni sebanyak 87 pelanggan.

Sumber data yang digunakan adalah data primer, yaitu data yang bersumber dari obyek atau responden yang diberi kuesioner. Untuk memperoleh data serta keterangan yang diperoleh dalam penelitian ini, penulis menggunakan teknik pengumpulan data dengan penyebaran kuesioner.

Penelitian ini menggunakan metode survei dengan menggunakan kuisioner yang berisi tentang pernyataan-pernyataan maka dalam teknik pengukuran data peneliti menggunakan Skala Likert. Menurut Sugiyono, (2014) Skala likert digunakan untuk mengukur sikap, pendapat, dan persepsi seseorang atau sekelompok orang tentang fenomena sosial. Penjabaran variabel menjadi indikator variabel dijadikan sebagai titik tolak untuk menyusun item-item instrumen yang dapat berupa pernyataan atau pertanyaan.

Statistik deskriptif melibatkan transformasi data mentah menjadi bentuk yang akan memberikan informasi untuk menggambarkan serangkaian faktor dalam suatu situasi. Hal ini dilakukan dengan memesan dan memanipulasi data mentah yang dikumpulkan (Sekaran, 2010). Dalam penelitian ini statistic deskriptif dilakukan untuk memberikan gambaran atau deskripsi atas data yang telah dikumpulkan dengan melihat dari nilai rata-rata, nilai tertinggi dan nilai terendah (Ghozali, 2013).

Model struktural (inner model) merupakan model struktural untuk memprediksi hubungan kausalitas antar variabel laten. Melalui proses bootstrapping, parameter uji $T$ statistic diperoleh untuk memprediksi adanya hubungan kausalitas. Model struktural (inner model) dievaluasi dengan melihat persentase varian yang dijelaskan oleh nilai $R 2$ untuk variabel dependen dengan menggunakan ukuran Stone-Geisser Q-squaretest (Stone, 1974; Geisser, 1975 dalam Kalnadi 2013).

Menurut Hartono (2008) dalam Jogiyanto dan Abdillah (2009) menjelaskan bahwa ukuran signifikansi keterdukungan hipotesis dapat digunakan perbandingan nilai T-table dan $T$-statistic. Jika $T$-statistic lebih tinggi dibandingkan nilai T-table, berarti hipotesis terdukung atau diterima. Dalam penelitian ini untuk tingkat keyakinan 95 persen (alpha 95 persen) maka nilai T-table untuk hipotesis satu ekor (one-tailed) adalah >1,68023. Analisis PLS (Partial Least Square) yang digunakan dalam penelitian ini dilakukan dengan menggunakan program SmartPLS versi 2.0.m3 yang dijalankan dengan media komputer. 
INOBIS: Jurnal Inovasi Bisnis dan Manajemen Indonesia

Volume 1, Nomor 4, September 2018

Dyah Sawitri; Wisma Miftahur Rozi; Gendut Budi Wahyono; Eko Budi Siswandoyo

\section{Hasil dan Pembahasan}

\section{Hasil Analisis Menggunakan PLS}

\section{Evaluasi Measurement (Outer) Model}

Convergent validity dari measurement model dengan indikator refleksif dapat dilihat dari korelasi antara score item/indikator dengan score konstruknya. Indikator individu dianggap reliabel jika memiliki nilai korelasi di atas 0,70 . Namun demikian pada riset tahap pengembangan skala, loading 0,50 sampai 0,60 masih dapat diterima (Imam Ghozali, 2006). Berdasarkan pada result for outer loading (Tabel 3) maka seluruh indikator memiliki loading di atas 0,50 dan signifikan. Output Smart PLS untuk loading factor secara detail disajikan pada Tabel 3.

Pengujian validitas untuk indikator reflektif menggunakan korelasi antara skor item dengan skor konstruknya. Pengukuran dengan indikator reflektif menunjukkan adanya perubahan pada suatu indikator dalam suatu konstruk jika indikator lain pada konstruk yang sama berubah (atau dikeluarkan dari model). Indikator reflektif cocok digunakan untuk mengukur persepsi sehingga penelitian ini menggunakan indikator reflektif. Dari Tabel 3, diketahui bahwa seluruh dimensi telah memenuhi convergent validity karena memiliki nilai loading lebih dari 0.50 .

Tabel 3.

Result For Outer Loading

\begin{tabular}{|l|l|l|l|l|l|}
\hline \multirow{2}{*}{ Indicator } & \multicolumn{3}{|c|}{ Nilai Loading } & Keterangan \\
\hline & KPL & KHR & KPC & KPS & \\
\hline KPL2 & 0.775 & & & $\begin{array}{l}\text { Memenuhi } \\
\text { convergent } \\
\text { validity }\end{array}$ \\
\hline KPL3 & 0.786 & & & $\begin{array}{l}\text { Memenuhi } \\
\text { convergent } \\
\text { validity }\end{array}$ \\
\hline KPL4 & 0.706 & & $\begin{array}{l}\text { Memenuhi } \\
\text { convergent } \\
\text { validity }\end{array}$ \\
\hline KPL5 & 0.671 & & $\begin{array}{l}\text { Memenuhi } \\
\text { convergent } \\
\text { validity }\end{array}$ \\
\hline KHR1 & & 0.828 & $\begin{array}{l}\text { Memenuhi } \\
\text { convergent } \\
\text { validity }\end{array}$ \\
\hline KHR2 & & 0.882 & $\begin{array}{l}\text { Memenuhi } \\
\text { convergent } \\
\text { validity }\end{array}$ \\
\hline KPC1 & & $\begin{array}{l}\text { Memenuhi } \\
\text { convergent } \\
\text { validity }\end{array}$ \\
\hline
\end{tabular}


INOBIS: Jurnal Inovasi Bisnis dan Manajemen Indonesia Volume 1, Nomor 4, September 2018

Dyah Sawitri; Wisma Miftahur Rozi; Gendut Budi Wahyono; Eko Budi Siswandoyo

\begin{tabular}{|l|l|l|l|l|l|}
\hline \multirow{2}{*}{ Indicator } & \multicolumn{3}{|c|}{ Nilai Loading } & Keterangan \\
\cline { 2 - 5 } KPC2 & KPL & KHR & KPC & KPS & \\
\hline KPS1 & & & 0.733 & & $\begin{array}{l}\text { Memenuhi } \\
\text { convergent } \\
\text { validity }\end{array}$ \\
\hline KPS2 & & 0.805 & $\begin{array}{l}\text { Memenuhi } \\
\text { convergent } \\
\text { validity }\end{array}$ \\
\hline KPS3 & & 0.878 & $\begin{array}{l}\text { Memenuhi } \\
\text { convergent } \\
\text { validity }\end{array}$ \\
\hline KPS4 & & & 0.571 & $\begin{array}{l}\text { Memenuhi } \\
\text { convergent } \\
\text { validity }\end{array}$ \\
\hline
\end{tabular}

Sumber: Data primer diolah, Tahun 2017

Diagram path yang dihasilkan setelah menjalankan program Smart PLS untuk seluruh konstruk disajikan pada Gambar 1.

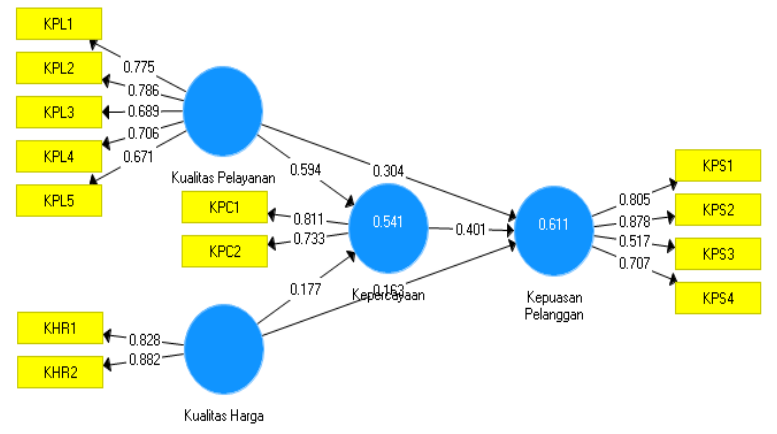

Gambar 1.

Konstruk Model Beta

Sumber: Data primer diolah, Tahun 2017.

\section{Discriminat Validity}

Discriminat validity dari model pengukuran dengan indikator refleksif dinilai berdasarkan cross loading pengukuran dengan konstruk. Jika korelasi konstruk dengan item pengukuran lebih besar daripada ukuran konstruk lainnya, maka hal itu menunjukkan bahwa konstruk laten memprediksi ukuran pada blok mereka lebih baik daripada ukuran pada blok lainnya. Cara lain mengukur discriminat validity adalah melihat nilai square root of average variance extracted. (AVE). Nilai yang disarankan adalah di atas 0,5. Berikut adalah nilai AVE dalam penelitian yang dihasilkan pada Tabel 4. 
INOBIS: Jurnal Inovasi Bisnis dan Manajemen Indonesia

Volume 1, Nomor 4, September 2018

Dyah Sawitri; Wisma Miftahur Rozi; Gendut Budi Wahyono; Eko Budi Siswandoyo

Tabel 4.

Average Variance Extracted (AVE)

\begin{tabular}{|c|c|}
\hline KONSTRUK & AVE \\
\hline KPL & 0.564 \\
\hline KHR & 0.732 \\
\hline KPC & 0.598 \\
\hline KPS & 0.546 \\
\hline
\end{tabular}

Sumber: Data primer diolah, Tahun 2017

Nilai AVE pada Tabel 4 memperoleh angka di atas 0,5 untuk semua konstruk, yaitu Kualitas pelayanan memiliki nilai AVE 0.564, KHR 0.732, KPC 0.598, dan KPS 0.546 hal ini berarti semua konstruk memiliki discriminat validity yang tinggi.

\section{Composite Reliability}

Pengujian selanjutnya adalah composite reliability dari blok indikator yang mengukur konstruk. Suatu konstruk dikatakan reliable jika nilai composite reliability di atas 0,60 (Imam Ghozali, 2006). Hasil outer model loading yang menunjukkan composite relaibilty masingmasing konstruk, disajikan pada Tabel 5.

Tabel 5.

Composite Reliability

\begin{tabular}{|c|c|}
\hline Konstruk & $\begin{array}{l}\text { Composite } \\
\text { Reliability }\end{array}$ \\
\hline KPL & 0.805 \\
\hline KHR & 0.845 \\
\hline KPC & 0.748 \\
\hline KPS & 0.823 \\
\hline
\end{tabular}

Sumber: Data primer diolah, Tahun 2017

Berdasarkan hasil perhitungan pada Tabel 5 menunjukkan composite reliablity yang memuaskan yaitu KPL (0.805), KHR (0.845), KPC (0.748), dan KPS (0.823). Jadi dapat disimpulkan bahwa masing-masing konstruk memiliki reliabilitas yang tinggi, hal ini dapat dilihat dari nilai composite reliability seluruh konstruk lebih besar dari 0,60.

\section{Evaluasi Model Struktural atau Inner Model}

Menilai inner model adalah mengevaluasi hubungan antar konstruk laten seperti yang telah dihipotesiskan dalam penelitian ini, yaitu bagaimana hubungan model pertama kualitas pelayanan dan harga terhadap kepercayaan, dan hubungan model kedua pengaruh kualitas pelayanan, kualitas harga dan kepercayaan terhadap kepuasan. Perhitungan R square yang terbentuk dari dua model tersebut dapat dilihat pada Tabel 6.

\begin{tabular}{|l|c|c|}
\multicolumn{3}{c}{ Tabel 6. } \\
\multicolumn{1}{|c|}{ R-Square } \\
\hline \multicolumn{1}{|c|}{ Model } & $\begin{array}{c}\text { R } \\
\text { Square }\end{array}$ & $\begin{array}{c}\text { Adj. R. } \\
\text { Square }\end{array}$ \\
\hline $\begin{array}{l}\text { KPL dan } \\
\text { KHR } \rightarrow \text { KPC }\end{array}$ & 0.541 & 0.530 \\
\hline
\end{tabular}


INOBIS: Jurnal Inovasi Bisnis dan Manajemen Indonesia

Volume 1, Nomor 4, September 2018

Dyah Sawitri; Wisma Miftahur Rozi; Gendut Budi Wahyono; Eko Budi Siswandoyo

\begin{tabular}{|l|l|l|}
\hline $\begin{array}{l}\text { KPL, KHR, } \\
\text { dan } \\
\text { KPC } \rightarrow \text { KPS }\end{array}$ & 0.611 & 0.597 \\
\hline
\end{tabular}

Sumber : Data primer diolah, Tahun 2017

\section{Pengujian Hipotesis}

Hasil analisis jalur yang disajikan pada Tabel 7 dan Tabel 8, akan digunakan untuk melihat pengaruh antar variabel dengan melihat taraf signifikasi antar variabel, serta hubungan antar variabel. Untuk melihat pengaruh antar variabel dapat dilihat dari besarnya nilai Adjusted R Square $\left(\mathrm{r}^{2}\right)$ dengan cara menghitung besarnya Koefisien Determinasi (KD) menggunakan rumus $\mathrm{KD}=\mathrm{r}^{2} \times 100 \%$. Sedangkan untuk melihat taraf signifikasi antar variabel digunakan Sig penelitian, jika Sig penelitian lebih kecil dari 0,05 (Sig $\leq$ 0,05), maka dinyatakan terdapat pengaruh signifikan antar variabel. Jika nilai Sig penelitian lebih besar dari nilai 0,05 ( $\mathrm{Sig} \geq 0,05)$, maka dinyatakan pengaruh antar variabel tidak signifikan atau dapat juga dilihat dengan menggunakan uji t. Apabila nilai $t_{\text {hitung }}$ lebih besar darit ${ }_{\text {tabel }}$ $\left(t_{\text {hitung }}>t_{\text {tabel }}\right)$ maka pengaruh antar variabel adalah signifikan. Sebaliknya jika nilai $t_{\text {hitung }}$ lebih kecil dari $t_{\text {tabel }}\left(t_{\text {hitung }}<t_{\text {tabel }}\right)$ maka pengaruh antar variabel adalah tidak signifikan.

Tabel 7.

Analisis Jalur Pengaruh Langsung

\begin{tabular}{|l|c|c|c|c|}
\hline Jalur 1 & $\begin{array}{c}\text { Original } \\
\text { Sampel } \\
\text { (Beta) }\end{array}$ & t-Statistik & $\begin{array}{c}\text { p-Value } \\
(\text { Sig })\end{array}$ & Keterangan \\
\hline $\mathrm{X} 1(\mathrm{KPL}) \rightarrow \mathrm{Z1}(\mathrm{KPC})$ & 0.594 & 7.699 & 0.000 & Signifikan \\
\hline $\mathrm{X} 2(\mathrm{KHR}) \rightarrow \mathrm{Z1}(\mathrm{KPC})$ & 0.177 & 1.880 & 0.601 & $\begin{array}{c}\text { Tidak } \\
\text { signifikan }\end{array}$ \\
\hline $\mathrm{X} 1(\mathrm{KPL}) \rightarrow \mathrm{Y} 1(\mathrm{KPS})$ & 0.304 & 2.145 & 0.032 & Signifikan \\
\hline $\mathrm{X} 2(\mathrm{KHR}) \rightarrow \mathrm{Y} 1(\mathrm{KPS})$ & 0.163 & 1.365 & 0.173 & $\begin{array}{c}\text { Tidak } \\
\text { signifikan }\end{array}$ \\
\hline $\mathrm{Z1}(\mathrm{KPC}) \rightarrow \mathrm{Y}(\mathrm{KPS})$ & 0.401 & 3.791 & 0.000 & Signifikan \\
\hline
\end{tabular}

Sumber : Data primer diolah, Tahun 2017

\section{Koefisien Jalur Pengaruh Variabel Kualitas Pelayanan (X1) dan Kualitas Harga (X2) terhadap Variabel Kepercayaan (Z1)}

Hasil ini dapat dijelaskan bahwa nilai $t_{\text {hitung }}$ lebih kecil dari $\mathrm{t}_{\text {tabel }}$ dan nilai $\mathrm{p}$-value lebih besar dari nilai $\alpha$. Serta nilai koesfisean jalur (beta) memiliki angka positif, maka hasilnya tidak signifikan dan positif. Hasil ini dapat disimpulkan, menunjukkan bahwa variabel Kepercayaan (Z1) tidak dapat dijelaskan secara langsung oleh variabel Kualitas Harga (X2) atau hipotesis (H2) di tolak.

\section{Koefisien Jalur Pengaruh Variabel Kualitas Pelayanan (X1), Kualitas Harga (X2) dan Kepercayaan (Z1) terhadap Kepuasan Konsumen (Y1).}

Hasil ini dapat dijelaskan bahwa nilai $t_{\text {hitung }}$ lebih besar dari $t_{\text {tabel }}$ dan nilai $p$-value lebih kecil dari nilai $\alpha$. Serta nilai koefisien jalur (beda) memiliki angka positif, maka hasilnya adalah signifikan dan positif. Hasil ini dapat disimpulkan menunjukkan bahwa variabel 
INOBIS: Jurnal Inovasi Bisnis dan Manajemen Indonesia Volume 1, Nomor 4, September 2018

Dyah Sawitri; Wisma Miftahur Rozi; Gendut Budi Wahyono; Eko Budi Siswandoyo

Kepuasan pelanggan (Y1) dapat dijelaskan langsung oleh variabel Kepercayaan (Z1) atau hipotesis (H5) diterima.

Koefisien Jalur Pengaruh Kualitas Pelayanan dan kualitas harga Secara Tidak Langsung Terhadap Kepuasan pelanggan melalui kepercayaan

Berdasarkan hasil perhitungan statistik pada Tabel 8, menunjukkan bahwa Kualitas Harga berpengaruh tidak signifikan terhadap Kepuasan pelanggan dengan koefisien jalur sebesar 0.177 dan nilai sig sebesar 0.601 (sig probabilitas > 0,05). Selanjutnya dilakukan pengujian pengaruh tidak langsung antara Kualitas Harga terhadap Kepuasan pelanggan melalui Kepercayaan, dari hasil perhitungan menunjukkan koefisien jalur koefisien sebear 0.071 dan nilai sig sebesar 0.000 sehingga pengaruh tidak langsung adalah signifikan, karena mempunyai nilai positif dengan demikian dapat disimpulkan bahwa penerapan Kualitas Harga akan meningkatkan Kepuasan pelanggan melalui kepercayaan, apabila dengan penerapan Kualitas Harga yang di tambah dengan kepercayaan baik maka akan mampu kepuasan pelanggan.

Tabel 8.

Analisis Jalur Pengaruh Tidak Langsung

\begin{tabular}{|l|c|c|c|c|}
\hline \multicolumn{1}{|c|}{ Jalur 2 } & $\begin{array}{c}\text { Original Sampel } \\
\text { (Beta) }\end{array}$ & t-Statistik & p-Value (Sig) & Keterangan \\
\hline $\begin{array}{l}\mathrm{X} 1(\mathrm{KPL}) * Z 1(\mathrm{~K} \\
\mathrm{PC}) \rightarrow \mathrm{Y} 1 \\
(\mathrm{KPS})\end{array}$ & 0.594 & $\begin{array}{c}0.594 \mathrm{x} \\
0.401=0.238\end{array}$ & 0.000 & Signifikan \\
\hline $\begin{array}{l}\mathrm{X} 2(\mathrm{KHR}) * \mathrm{Z} 1( \\
\text { KPC }) \rightarrow \mathrm{Y} 1 \\
(\mathrm{KPS})\end{array}$ & 0.177 & $\begin{array}{c}0.177 \times 0.401 \\
=0.071\end{array}$ & 0.000 & Signifikan \\
\hline $\begin{array}{l}\mathrm{Z} 1(\mathrm{KPC}) \rightarrow \mathrm{Y} 1 \\
(\mathrm{KPS})\end{array}$ & 0.401 & 0.304 & 0.000 & Signifikan \\
\hline $\begin{array}{l}\mathrm{X} 1(\mathrm{KPL}) \rightarrow \mathrm{Y} 1 \\
(\mathrm{KPS})\end{array}$ & 0.163 & & 0.032 & Signifikan \\
\hline $\begin{array}{l}\mathrm{X} 2(\mathrm{KHR}) \rightarrow \mathrm{Y} 1 \\
(\mathrm{KPS})\end{array}$ & 0.173 & Tidak signifikan \\
\hline
\end{tabular}

Sumber : Data primer diolah, Tahun 2017

\section{Pembahasan Hasil Penelitian}

\section{Pengaruh Kualitas Pelayanan Terhadap Kepuasan Konsumen Pada Hotel Purnama}

Berdasarkan temuan penelitian dapat diketahui bahwa kualitas pelayanan jasa yang diberikan oleh hotel purnama termasuk dalam kategori baik. Hal tersebut terlihat dari tingginya kecepatan pegawai dalam memberikan pelayanan dan kesesuaian pegawai dalam memberikan pelayanan dengan yang dijanjikan. Selain itu, pegawai juga memberikan informasi yang lengkap dan detail kepada setiap pengunjung. Hal tersebut nantinya memberikan pengaruh yang positif kepada kepuasangan pelanggan. Tingginya kepuasan pelanggan terlihat dari respon positif berupa menggunakan kembali jasa pelayanan hotel dalam jangka waktu dekat dan lama, bersedia merekomendasikan pelayanan yang diterima kepada teman atau orang lain, keluarga, rekan kerja, bersedia menggunakan berbagai jenis layanan yang ada saat ini, dan sebagainya. 
INOBIS: Jurnal Inovasi Bisnis dan Manajemen Indonesia

Volume 1, Nomor 4, September 2018

Dyah Sawitri; Wisma Miftahur Rozi; Gendut Budi Wahyono; Eko Budi Siswandoyo

\section{Pengaruh Kualitas Harga Terhadap Kepuasan Konsumen Pada Hotel Purnama}

Harga merupakan salah satu aspek yang dipertimbangkan oleh konsumen dalam memutuskan untuk penggunaan jasa. Berdasarkan hasil penelitian menunjukkan bahwa hraga tidak memberikan dampak signifikan terhadap kepuasan pelanggan. Hal tersebut dikarenakan beberapa faktor yang didasarkan pada temuan peneliti berupa pemberian diskon dan promo yang kurang tepat baik dari sisi waktu atau sasaran, tidak adanya informasi berupa iklan jika terjadi kenaikan harga pada periode waktu tetentu. Selain itu, diskon berdasarkan jumlah transaksi pemakaian hanya berlaku pada paket khusus, sehingga membuat jawaban responden tidak terlalu puas. Ketidakkonsistenan tersebut berdampak pada kepuasan pelanggan secara langsung.

Sedangkan harga yang disediakan Hotel Purnama termasuk dalam kategori baik, hal ini dapat dilihat dari harga yang terjangkau, harga yang lebih murah dibanding pesaingnya dan harga sesuai dengan kualitas pelayanan. Dalam penetapan harga pelu diperhatikan daya beli pelanggan, karena harga erat kaitannya dengan perspektif pelanggan. Pelanggan langsung merasakan perubahan harga yang ditawarkan. Hal ini sesuai dengan pernyataan sumarni (2000) yaitu penetapan harga bukan merupakan pekerjaan yang mudah. Seringkali perusahaan menetapkan harga terlalu berorientasi pada biaya dan kurang meninjau perubahan pasar. Oleh karena itu dalam menetapkan harga perlu diperhatikan pula daya beli pelanggannya agar pelanggan tidak beralih pada pesaing yang lain. Kualitas harga yang di tetapkan hotel Purnama tidak mempengaruhi kepuasan konsumen karena konsumen hotel Purnama meskipun banyak PNS rata-rata mereka menginap karena pemerintah atau didanai pemerintah sehingga harga tidak berpengaruh pada kepuasan konsumen.

\section{Pengaruh Kualitas Pelayanan Terhadap Kepercayaan Pada Hotel Purnama}

Kualitas pelayanan memegang peranan penting bagi terbentuknya sebuah kepercayaan. Berdasarkan hasil temuan penelitian dapat diketahui bahwa kepercayaan pelangan dapat terbentuk dari adanya kesesuaian antara janji yang diberikan dengan realisasinya. Selain itu, kepercayaan juga dapat dilihat dari kesesuaian informasi dan tingkat kesalahan yang dilkaukan oleh perusahaan sehingga pelanggan tidak kecewa. Kualitas pelayanan yang baik dapat dilihat dari kecepatan dan kesesuaian akan membentuk kepercayaan pelanggan terhadap perusahaan.

Pengaruh Kualitas Harga Terhadap Kepercayaan Pada Hotel Purnama

Berdasarkan hasil penelitian dapat diketahui bahwa tidak terdapat penagruh siginifikan kualitas harga terhadap kepercayaan. Pada industri jasa perhotelan kualitas pelayanan merupakan indikator utama disamping harga. Harga tidak memberikan pengaruh signifikan terhadap kepercayaan karena beberapa faktor, diantaranya ketidakkosistensian perusahaan dalam menetapkan harga. Selain itu, harga yang ditetapkan tidak sesuai dengan event atau waktu spesial, sehingga konsumen tidak percaya dengan ketetapan harga yang dilakukan hotel.

\section{Pengaruh Kepercayaan Terhadap Kepuasan Konsumen Pada Hotel Purnama}

Perusahaan menghasilkan jasa bertujuan untuk meningkatkan kepercayaan pelanggan dalam mencapai kepuasan. Oleh karena itu, kepercayaan pelanggan yang diberikan perusahaan dapat memenuhi kebutuhan pelanggan. Kepercayaan memegang pernanan penting dalam membentuk sebuah kepuasan. Hasil penelitian dapat diketahui bahwa kepercayan 
INOBIS: Jurnal Inovasi Bisnis dan Manajemen Indonesia

Volume 1, Nomor 4, September 2018

\section{Dyah Sawitri; Wisma Miftahur Rozi; Gendut Budi Wahyono; Eko Budi Siswandoyo}

konsumen hotel purnama termasuk dalam kategori tinggi yang dapat diidentifikasi melalui tingginya kesesuaian janji yang diberikan, kemampuan karyawan dalam pelayanan, perusahaan mampu menanggung resiko atas kesalahan yang dilaukan, serta kesesuaian informasi yang diberikan kepada konsumen. Kelima indikator tersebut menjadi acuan bahwa dengan semakin tinggnya kepercayaan akan menunjukkan kepuasan konsumen seperti adanya menggunakan layanan kembali dalam jangka waktu dekat, merekomendasikan kepada teman atau orang lain, seta bersedia menggunakan jenis layanan lain yang diberikan hotel. Semakin tinggi kepuasan pelanggan akan mendorong dan meningkatkan profitabilitas atau keuntungan hotel, sehingga hotel mempunyai daya saing yang tinggi.

Kepercayaan yang di berikan oleh hotel Purnama yaitu: adanya sertifikat yang di miliki oleh pegawai, adanya gambar bagaimana prosedur pelayanan yang di berikan hotel Purnama, adanya bukti fisik yang di sertai informasi fasilitas hotel.

\section{Pengaruh Tidak Langsung Kualitas Pelayanan Terhadap Kepuasan Konsumen Melalui Kepercayaan Pada Hotel Purnama}

Kepercayaan dapat berfungsi dengan baik sebagai variabel intervening disebabkan oleh beberapa faktor atau indikator. Perilaku konsumen untuk menggunakan jasa perhotelan di masa akan datang sangat bergantung pada tingkat kepercayaan seseorang terhadap jenis layanan yang diberikan hotel. Apabila kualitas pelayanan diberikan secara baik yang dapat terlihat dari kecepatan, kesesuaian janji, jaminan, perhatian, serta kelengkapan sarana dan prasarana akan membentuk sikap yang percaya terhadap hotel tersebut. Sikap percaya dapat dilihat dari kesesuaian janji dan informasi yang diberikan akan membuat konsumen mnejadi puas karena tidak ada satu hal yang bisa dilanggar. Semakin tinggi kualitas pelayanan yang ditambah dengan tingginya tingkat kepercayaan akan membentuk kepuasan pelanggan.

\section{Pengaruh Tidak Langsung Kualitas harga Terhadap Kepuasan Konsumen Melalui kepercayaan Pada Hotel Purnama}

Kepercayaan dapat berfungsi dengan baik sebagai variabel intervening disebabkan oleh beberapa faktor atau indikator. Perilaku konsumen untuk menggunakan jasa perhotelan di masa akan datang sangat bergantung pada tingkat kepercayaan seseorang terhadap jenis layanan yang diberikan hotel. Apabila kualitas harga diberikan secara baik yang dapat terlihat dari adanya diskon, penetapan harga yang terjangkau, adanya jaminan yang diberikan, dan kesesuaian harga dengan pelayan yang diberikan akan membentuk sikap yang percaya terhadap hotel tersebut. Kepercayaan konsumen dapat dilihat dari kesesuaian janji dan informasi yang diberikan akan membuat konsumen menjadi puas selama menerima pelayanan. Semakin tinggi kualitas harga yang ditambah dengan tingginya tingkat kepercayaan, maka akan mempengaruhi semakin tingginya kepuasan pelanggan

\section{Kesimpulan}

Berdasarkan hasil analisa data serta pembahasan yang telah dilakukan, maka hasil penelitian ini dapat disimpulkan sebagai berikut:

1. Hasil penelitian menunjukan bahwa variable Kualitas Pelayanan berpengaruh terhadap kepuasan pelanggan. Hal ini menunjukan bahwa semakin baik Kualitas Pelayanan yang diterapkan pada Hotel Purnama akan meningkatkan kepuasan pelanggan. 
INOBIS: Jurnal Inovasi Bisnis dan Manajemen Indonesia

Volume 1, Nomor 4, September 2018

\section{Dyah Sawitri; Wisma Miftahur Rozi; Gendut Budi Wahyono; Eko Budi Siswandoyo}

2. Hasil penelitian menunjukan bahwa Kualitas harga tidak berpengaruh terhadap kepuasan pelanggan Hal ini menunjukan bahwa kualitas harga tidak berpengaruh terhadap kepuasan pelanggan.

3. Hasil penelitian menunjukan bahwa Kualitas Pelayanan berpengaruh terhadap Kepercayaan. Hal ini menunjukan bahwa semakin baik Kualitas Pelayanan yang diterapkan akan meningkatkan Kepercayaan pelangggan.

4. Hasil penelitian menunjukan bahwa Kualitas harga tidak berpengaruh terhadap Kepercayaan. Hal ini menunjukan bahwa semakin baik kualitas harga yang diterapkan tidak akan meningkatkan Kepercayaan pelangggan.

5. Hasil penelitian menunjukan bahwa kepercayaan berpengaruh terhadap kepuasan pelanggan. Hal ini menunjukan bahwa semakin tinggi tingkat kepercayaan akan meningkatkan kepuasan pelangggan.

6. Hasil penelitian menunjukan bahwa Kualitas Pelayanan berpengaruh terhadap kepuasan melalui kepercayaan. Hal ini menunjukan bahwa semakin baik Kualitas Pelayanan maka semakin tinggi pula kepercayaan konsumen terhadap perusahaan, sehingga akan meningkatkan kepuasan konsumen.

7. Hasil penelitian menunjukan bahwa Kualitas harga berpengaruh terhadap kepuasan melalui kepercayaan. Hal ini menunjukan bahwa semakin tinggi Kualitas harga maka semakin tinggi juga kepercayaan konsumen. Sehingga akan meningkatkan kepuasan konsumen.

\section{Saran}

Diharapkan pihak perusahaan dapat mempertahankan assurance atau jaminan yang di berikan. Karena berdasarkan penelitian ini dapat di ketahui besarnya pengaruh assurance dalam mempengaruhi kepuasan konsumen. Upaya tersebut dapat dilakukan dengan mempertahankan seperti :

a) Pegawai memiliki rasa percaya diri, ketika memberikan pelayanan terhadap konsumen.

b) Pegawai memiliki sikap sopan dalam memberikan pelayanan terhadap konsumen.

c) Pegawai memiliki pengetahuan yang baik dalam memberikan pelayanan yang konsumen butuhkan.

d) Pegawai memberikan rasa aman dalam melayani konsumen

e) Pegawai memberikan rasa nyaman saat melayani.

\section{Daftar Pustaka}

Ali Hasan. 2008. Marketing. Media Utama, Yogyakarta.

Arikunto, S. 2010. Prosedur penelitian : Suatu Pendekatan Praktik. (Edisi Revisi). Jakarta : Rineka Cipta.

Engel. James.F.Roger. D.Black Well And Paul. W. Miniard, 1995. Perilaku Konsumen.Jakarta.Bina Rupa Aksara.Hal. 3.

Ghozali, Imam. 2013. Aplikasi Analisis Multivariare dengan Program SPSS. Edisi Ketujuh. Semarang: BAdan Penerbit Universitas Diponegoro.

Hartono, Jogiyanto. 2008. Teori Pertofolio dan Analisis Investasi. Yogyakarta: BPFE.

Kalnadi, D. 2013. Pengukuran Penerimaan dan Penggunaan Teknologi Pada UMKM Dengan Menggunakan Metode UTAUT. Jurusan Adm.Bisnis, Fakultas ISIP, Universitas Lampung. (unpublish).

Kotles Philip, dan Gary Amstrong. 2010. Principles Of Marketing. Global Edition, 14 Edition, Pearson Education. 
INOBIS: Jurnal Inovasi Bisnis dan Manajemen Indonesia

Volume 1, Nomor 4, September 2018

Dyah Sawitri; Wisma Miftahur Rozi; Gendut Budi Wahyono; Eko Budi Siswandoyo

Singarimbun, Masri dan Sofian Effendi, Metode Penelitian Survei, Jakarta: LP3ES, 2008. Sugiyono. 2012. Metode Penelitian Kuantitatif Kualitatif dan R\&D. Bandung: Alfabeta

Sugiyono. 2014. Metode Penelitian Kuantitatif, Kualitatif, dan Kombinasi (Mixed Methods). Bandung : Alfabeta. 